\title{
Phosphate Solubilization and Growth Promotion of Rubber Tree (Hevea brasiliensis Muell. Arg.) by Trichoderma Strains
}

\author{
Athakorn Promwee ${ }^{1}$, Montree Issarakraisila ${ }^{1}$, Warin Intana ${ }^{1}$, Chiradej Chamswarng ${ }^{2} \&$ Punnawich Yenjit $^{3}$ \\ ${ }^{1}$ School of Agricultural Technology, Walailak University, Nakhon Si Thammarat, Thailand \\ ${ }^{2}$ Department of Plant Pathology, Faculty of Agriculture at Kamphaeng Saen, Kasetsart University, Kamphaeng \\ Saen Campus, Nakhon Pathom, Thailand \\ ${ }^{3}$ Faculty of Agricultural and Industrial Technology, Nakhon Sawan Rajabhat University, Nakhon Sawan, \\ Thailand
}

Correspondence: Athakorn Promwee, School of Agricultural Technology, Walailak University, Nakhon Si Thammarat 80161, Thailand. E-mail: p_athakorn@hotmail.com

Received: June 4, 2014 Accepted: June 20, 2014 Online Published: August 15, 2014

doi:10.5539/jas.v6n9p8 URL: http://dx.doi.org/10.5539/jas.v6n9p8

\begin{abstract}
The role of Trichoderma species as phosphate solubilizing microorganism was studied in vitro, by means of the Modified Pikovskaya's Broth medium (MPB) and in vivo, under greenhouse conditions using Rock Phosphate (RP) as a source of phosphorus (P). In broth medium, Trichoderma strain FR-NST-009 gave the highest P-solubilization (80.25\%), followed by FR-NST-353 (77.51\%), CB-Pin-01 (66.91\%), RB-NST-028 (46.05\%), and RB-NST-003 (21.20\%) as compared with a control (broth medium non-inoculated with Trichoderma strain) after incubation at room temperature $\left(27 \pm 2{ }^{\circ} \mathrm{C}\right)$ for 7 days. In addition, the treatments with Trichoderma species provided the final $\mathrm{pH}$ of broth culture lower than the control. Three kinds of organic acids including citric acid, lactic acid and succinic acid were detected by High Performance Liquid Chromatography (HPLC) in all treatments inoculated with Trichoderma strain. Trichoderma species produced citric acid in higher than lactic acid and succinic acid. Production of organic acids by Trichoderma species is one of the mechanisms for phosphate solubilization. In greenhouse conditions, at 60 days after planting, the treatments with Trichoderma strain FR-NST-009+RP provided the percentage of available phosphorus increasing more than the control 1 (with only RP) to $14.91 \%$. However, after 60 days, the available phosphorus in the planting medium continually decreased in all treatments. At 180 days after planting, the treatments with FR-NST-009+RP increased plant height $(22.19 \%)$, stem circumference $(13.81 \%)$, leaf number $(71.43 \%)$, total phosphorus in the rubber tree leaves $(18.90 \%)$, shoot fresh weight $(43.95 \%)$, root fresh weight $(19.36 \%)$, shoot dry weight $(39.96 \%)$, and root dry weight $(21.13 \%)$, as compared with the control 1 (with only RP) Furthermore, the treatments with FR-NST-009+RP provided the population of Trichoderma species in the planting medium with $1.78 \times 10^{5}$ Colony-Forming Units (CFU) per gram planting medium and gave the root colonization percentages with $100.00 \%$. The selected indigenous strain, FR-NST-009 was Trichoderma harzianum identified by using morphological characteristics.
\end{abstract}

Keywords: Trichoderma spp., phosphate solubilization, growth promotion, rubber tree

\section{Introduction}

Phosphorus (P) is one of macronutrients required for the growth and development of the plant. Generally, plants need phosphorus in $2,000 \mu \mathrm{g}$ per $1 \mathrm{~g}$ dry weight or $0.2 \%$. Phosphorus is the component of nucleic acids, phospholipids and adenosine triphosphate, ATP )Schachtman et al., 1998). Plants absorb phosphorus in inorganic form, dihydrogen phosphate ion $\mathrm{H}_{2} \mathrm{PO}_{4}{ }^{-}$(and hydrogen phosphate ion $\left(\mathrm{HPO}_{4}{ }^{2-}\right.$ ). The concentration of both $\mathrm{H}_{2} \mathrm{PO}_{4}{ }^{-}$and $\mathrm{HPO}_{4}{ }^{2-}$ depends on the $\mathrm{pH}$ of soil. However, phosphate ion was also absorbed by soil particle or fixed by the other element such as calcium $(\mathrm{Ca})$, magnesium $(\mathrm{Mg})$, aluminum $(\mathrm{Al})$, and iron $(\mathrm{Fe})$. Thus, insoluble phosphate forms, $\mathrm{Ca}_{3}\left(\mathrm{PO}_{4}\right)_{2}, \mathrm{AlPO}_{4}$, and $\mathrm{FePO}_{4}$, are not available to the plant (Altomare et al., 1999).

Trichoderma species are antagonistic fungi that have high efficacy to biological control of numerous plant diseases both in Thailand and in other countries, such as stem rot of tomato (Inwang \& Chamswarng, 1986), damping-off of cotton, Chinese kale, cucumber, yard long bean, okra, soybean and tomato (Chamswarng \& 
Inwang, 1987; Chamswarng \& Intanoo, 2002; Intana, 2003; Sangsridum, 2003; Promwee, 2008), Sclerotium blight of barley (Chamswarng et al., 1990), root rot of tangerine (Kitjaideaw et al., 2000), root rot of durian (Chamswarng et al., 1997), anthracnose of mango (Yenjit et al., 2004), root rot of lettuce (Lamool, 2006), flower rusty spot of Dendrobium orchid (Thienkhao, 2007), peanut brown root rot (Rojo et al., 2007), chickpea wilt (Dubey et al., 2007), sheath rot of rice (Sattasakulchai, 2009), avocado white root rot (Rosa \& Herrera, 2009), and ber fruit rot (Nallathambi et al., 2009).

Trichoderma species are not only having the ability in biological control of plant diseases, but also have high efficiency to promote plant growth and increase yield in several plants such as cucumber (Intana, 2003), chili (Inbar et al., 1994), marigold (Ousley et al., 1994), cabbage (Rabeendran et al., 2000), papaya )Morales-Payan \& Stall, 2004), vegetable amaranth (Chakhatrakan et al., 2006), and Chinese kale (Promwee, 2008). Phosphate solubilization of Trichoderma species is one of the mechanisms of these fungi as the plant growth promoting fungi. Moreover, Trichoderma species can produce phosphatases and several organic acids; both phosphatases and organic acids were found to solubilize insoluble phosphate. However, the ability of Trichoderma species depends on the kind and strain of Trichoderma and source of phosphate (Akintokun et al., 2007; Kapri \& Tewari, 2010; Promwee, 2011). In this sense, Thailand imported 5,583,276 tons of chemical fertilizer as valued 83,947 million Baht in 2012 (Office of Agricultural Economics, 2014). Consequently, application of high phosphate solubilizing fungi, Trichoderma species, in an organic farming system is an alternative method to reduce using chemical fertilizer for agricultural development in a sustainable agriculture system of Thailand.

Nevertheless, there are only a few reports about using Trichoderma species to solubilize insoluble phosphate both in Thailand and in other countries. Furthermore, the environments of southern part of Thailand are different from other parts; for instance, there are the high humidity and high level of rain, as a result, Trichoderma species habiting in soil of southern part may be different in the biodiversity. Hence, centring on southern Thailand, the objectives of this study were 1) to study the efficiency of indigenous Trichoderma species to solubilize insoluble phosphate both in vitro and under greenhouse conditions 2) to determine the organic acids produced by Trichoderma species and 3) to evaluate the efficacy of Trichoderma species for growth promotion of rubber tree under greenhouse conditions.

\section{Materials and Methods}

\subsection{Strains of Trichoderma Species}

Five strains of Trichoderma species used in this study include two indigenous strains (RB-NST-003, RB-NST-028) isolated from rubber planting soil samples in Nakhon Si Thammarat (Thailand), two indigenous strains (FR-NST-009, FR-NST-353) isolated from forest soil samples in the same study (Sattasakulchai, 2009), and Trichoderma harzianum strain CB-Pin-01, the commercial strain of Thailand.

The Trichoderma species were isolated from collecting rubber tree soil samples by soil dilution spread plate technique using Martin's medium (Martin, 1950), i.e, $\mathrm{KH}_{2} \mathrm{PO}_{4} 1.0 \mathrm{~g}, \mathrm{MgSO}_{4} \cdot 7 \mathrm{H}_{2} \mathrm{O} 0.5 \mathrm{~g}$, peptone $5.0 \mathrm{~g}$, dextrose $10.0 \mathrm{~g}$, rose bengal $0.033 \mathrm{~g}$, and agar $15.0 \mathrm{~g}$, dissolved in $1,000 \mathrm{ml}$ distilled water and supplemented with 100 $\mathrm{mg} / \mathrm{L}$ streptomycin. Ten grams of each soil sample were added into a $250 \mathrm{ml}$ flask containing $90 \mathrm{ml}$ of sterile water and mixed by a shaker (GFL 3020, Germany) at 120 RPM for $30 \mathrm{~min}$. Then, the soil suspension was diluted at $10^{-2}$ and $10^{-3}$ fold before $0.1 \mathrm{ml}$ of dilution was dropped on the surface of Martin's medium in a Petri dish. Soil suspension was spread on the surface of the medium with sterile glass rod before the dishes were sealed with paraffin film and incubated at room temperature $\left(27 \pm 2{ }^{\circ} \mathrm{C}\right)$ for 3-7 days.

The Trichoderma species growing on agar was selected and sub-cultured on Potato Dextrose Agar (PDA), i.e, potato $200.0 \mathrm{~g}$, dextrose $20.0 \mathrm{~g}$, agar $15.0 \mathrm{~g}$, and distilled water 1,000 ml (Intana, 2003; Promwee, 2008). A pure culture of Trichoderma species was identified based on its morphological and reproductive characteristics (Samuels et al., 2014).

\subsection{Testing of Phosphate Solubilization in vitro}

\subsubsection{Qualitative Estimation}

All strains of Trichoderma species were tested for their ability to solubilize inorganic phosphate on Modified Pikovskaya's Agar (MPA), i.e, rock phosphate $2.5 \mathrm{~g}$, glucose $13 \mathrm{~g}$, $\left(\mathrm{NH}_{4}\right) \mathrm{SO}_{4} 0.5 \mathrm{~g}, \mathrm{NaCl} 0.2 \mathrm{~g}, \mathrm{MgSO}_{4} \cdot 7 \mathrm{H}_{2} \mathrm{O}$ $0.1 \mathrm{~g}, \mathrm{KCl} 0.2 \mathrm{~g}$, yeast extract $0.5 \mathrm{~g}, \mathrm{MnSO}_{4} 0.0002 \mathrm{~g}, \mathrm{FeSO}_{4} \cdot 7 \mathrm{H}_{2} \mathrm{O} 0.0002 \mathrm{~g}$, agar $15 \mathrm{~g}$, pH adjusted to 7.2 , and dissolved in 1,000 $\mathrm{ml}$ distilled water (Pikovskaya, 1948).

One mycelial disc $(0.7 \mathrm{~cm}$ in diameter) of Trichoderma strain was put on the center of agar plate and incubated at room temperature for 3 days. Phosphate Solubilization Index (PSI) was measured and calculated by a formula as follows (Alam et al., 2002; Afzal \& Bano, 2008): 
PSI $=[$ colony diameter + halozone diameter $] /$ colony diameter

\subsubsection{Quantitative Estimation}

All strains of Trichoderma species were tested for their ability to solubilize inorganic phosphate in Modified Pikovskaya's Broth (MPB), i.e, rock phosphate $2.5 \mathrm{~g}$, glucose $13 \mathrm{~g},\left(\mathrm{NH}_{4}\right)_{2} \mathrm{SO}_{4} 0.5 \mathrm{~g}, \mathrm{NaCl} 0.2 \mathrm{~g}, \mathrm{MgSO}_{4} \cdot 7 \mathrm{H}_{2} \mathrm{O}$ $0.1 \mathrm{~g}, \mathrm{KCl} 0.2 \mathrm{~g}$, yeast extract $0.5 \mathrm{~g}, \mathrm{MnSO}_{4} 0.0002 \mathrm{~g}, \mathrm{FeSO}_{4} \cdot 7 \mathrm{H}_{2} \mathrm{O} 0.0002 \mathrm{~g}, \mathrm{pH}$ adjusted to 7.2 , and dissolved in 1,000 ml distilled water] (Pikovskaya, 1948).

Five mycelial discs $(0.7 \mathrm{~cm}$ in diameter) of Trichoderma strain were inoculated into $250 \mathrm{ml}$ Erlenmeyer flask containing $100 \mathrm{ml}$ of broth medium and incubated at room temperature in a shaker (GFL 3020) at 120 RPM for 7 days. Then, spores and mycelia of Trichoderma strains were removed from broth culture by filtration through $0.45 \mu \mathrm{m}$ Whatman No.1 and centrifuged by centrifuge (Z 200 A, HERMLE Labortechnik GmbH) at 5,000 RPM for $10 \mathrm{~min}$.

The supernatant of each culture was analyzed for $\mathrm{pH}$ by using a $\mathrm{pH}$ meter (CyberScan $\mathrm{pH}$ 510, Singapore). Phosphate concentration in the supernatant was estimated by spectrophotometric method (Fiske \& Subbarow, 1925; Saravanakumar et al., 2013). An aliquot of $750 \mu \mathrm{l}$ culture supernatant was mixed with $750 \mu 1$ of color reagent containing ammonium molybdate $\left(\left(\mathrm{NH}_{4}\right)_{6} \mathrm{Mo}_{7} \mathrm{O}_{24} \cdot 4 \mathrm{H}_{2} \mathrm{O}\right) 1.5 \%(\mathrm{w} / \mathrm{v})$, sulfuric acid $\left(\mathrm{H}_{2} \mathrm{SO}_{4}\right)$ solution $5.5 \%(\mathrm{v} / \mathrm{v})$ and ferrous sulfate $\left(\mathrm{FeSO}_{4}\right)$ solution $2.7 \%(\mathrm{w} / \mathrm{v})$ and then measured by a spectrophotometer (U-1800, Hitachi, Japan) at $600 \mathrm{~nm}$. The level of phosphate concentration was determined by using a standard graph of potassium dihydrogen phosphate $\left(\mathrm{KH}_{2} \mathrm{PO}_{4}\right)$ and expressed as equivalent phosphate in mg-P/L.

\subsection{Studying of Organic Acids Produced by Trichoderma Species}

\subsubsection{Qualitative Assessment}

All strains of Trichoderma species were tested for acid production on modified Pikovskaya's agar supplemented with bromocresol purple $(100.0 \mathrm{mg} / \mathrm{L})$. One mycelial disc $(0.7 \mathrm{~cm}$ in diameter) of Trichoderma strain was put on the center of agar plate and incubated at room temperature for 7 days. The phosphate solubilization activity of acid production was observed that Trichoderma strain turned the agar plate from purple to yellow in zones of acidification (Vazquez et al., 2000; Hoyos-Carvajal et al., 2009).

\subsubsection{Quantitative Assessment}

Eleven of organic acids such as acetic acid, citric acid, fumaric acid, gluconic acid, glutaric acid, lactic acid, maleic acid, malic acid, oxalic acid, succinic acid and tartaric acid were analyzed by high performance liquid chromatography (HPLC) (Waters alliance 2690, Waters) and compared with the standard (AOAC, 2000). Supernatant of samples in broth medium was passed through $0.45 \mu \mathrm{m}$ syringe filters and injected with $20 \mu \mathrm{l}$ injection loop into the column. These were determined by Metacarb $\mathrm{H}$ plus column (Varian), mobile phase 0.001 $\mathrm{N}$ sulfuric acid $\left(\mathrm{H}_{2} \mathrm{SO}_{4}\right)$ at the flow rate of $0.4 \mathrm{ml} / \mathrm{min}$. The column was set at $50{ }^{\circ} \mathrm{C}$ temperature. Each of organic acids produced by Trichoderma species was expressed in $\mathrm{mg} / \mathrm{L}$.

\subsection{Testing of Phosphate Solubilization in vivo (Under Greenhouse Conditions)}

Two strains of Trichoderma species (FR-NST-009 and CB-Pin-01) were tested for phosphate solubilization under greenhouse condition. Fresh culture of Trichoderma strain was prepared according to the method of Chamswarng and Intanoo (2002) and applied at $100 \mathrm{~g} /$ pot into the planting medium, i.e, $10 \mathrm{~kg}$ of soil $(\mathrm{pH}=5.05$, Total $\mathrm{N}=0.17 \%$, Available $\mathrm{P}=10.72 \mathrm{mg} / \mathrm{kg}$, and Exchangeable $\mathrm{K}=62.88 \mathrm{mg} / \mathrm{kg}$ ) collected from rubber planted area in Nakhon Si Thamarat (Thailand), mixed with $2 \mathrm{~kg}$ of cow manure (Total $\mathrm{N}=1.10 \%$, Total $\mathrm{P}=0.48 \%$, Total $\mathrm{K}=1.68 \%$ ), and supplemented with $200 \mathrm{~g} /$ pot of Rock Phosphate (RP). The 6-month-old rubber tree clone RRIM 600 was then planted in 15 inch diameter plastic pot.

The treatments were FR-NST-009+RP, CB-Pin-01+RP, contro1 1 (with only RP) and control 2 (without RP). Completely Randomized Design (CRD) with 4 replications per treatment and 3 plants per replication was used in this study. The parameters were estimated on this item as follows.

\subsubsection{Growth and Development Parameters}

At 180 days after planting, plant height of rubber tree was measured from the planting medium surface of the uppermost leaf sheath with a meter stick and expressed in $\mathrm{cm}$, stem circumference of rubber tree was estimated with tape measure and shown in $\mathrm{cm}$, and leaf number of rubber tree was counted and shown in the leaves per plant. For shoot and root fresh weights, these were harvested, weighed with an electronic analytical balance (Sartorius CP32032S, Germany), and shown in gram per plant. For shoot and root dry weights, shoot and root of rubber tree were air dried in hot air oven (WTE binder, Germany) at $60{ }^{\circ} \mathrm{C}$ for 7 days. Then, dried shoot and root of rubber tree were weighed with an electronic analytical balance and shown in gram per plant. 


\subsubsection{Population and Root Colonization of Trichoderma Species}

The population of Trichoderma species in the planting medium was studied by a dilution plate technique using Martin's medium at 0, 6, 120 and 180 days after planting according to the method of Intana (2003) and Promwee (2008). For root colonization of Trichoderma species, at 180 days after planting, root colonization of Trichoderma species was studied using Martin's medium according to the method of Intana (2003); Promwee (2008).

\subsubsection{Chemical Analysis}

Available phosphorus in the planting medium was extracted using $0.03 \mathrm{M} \mathrm{NH}_{4} \mathrm{~F}$ in $0.10 \mathrm{M} \mathrm{HCl}$ (Bray II solution), and its concentration was analyzed using the molybdenum blue method (AOAC, 2000), expressed in $\mathrm{mg} / \mathrm{kg}$. The $\mathrm{pH}$ of the planting medium was determined using soil: $\mathrm{H}_{2} \mathrm{O}$ at $1: 2.5 \mathrm{w} / \mathrm{v}$ by $\mathrm{pH}$ meter (CyberScan $\mathrm{pH}$ 510, Singapore) at $0,6,120$ and 180 days after planting. Finally, total phosphorus in rubber tree leaves was determined by the vanadomolybdate method (AOAC, 2000) and expressed in $\mathrm{mg} / \mathrm{kg}$ at 180 days after planting.

\subsection{Identification of Trichoderma Strain to Species Levels}

The high efficacy strain of Trichoderma obtained from the in vitro and in vivo tests was identified to species level by using morphological characteristics under compound microscope (Nikon YS100, Japan) and scanning electron microscope, SEM (JEOL, JSM5600LV, England) according to interactive key to species of Samuels et al. (2014) and compared with previous reports (Intana, 2003; Promwee, 2008; Sattasakulchai, 2009).

\subsection{Statistical Analysis}

All data were subjected to analysis of variance (ANOVA) followed by a comparison using Duncan's Multiple Range Test at $\mathrm{P}<0.05$.

\section{Results and Discussion}

\subsection{Testing of Phosphate Solubilization in vitro}

For the qualitative estimation of phosphate solubilization, all strains of Trichoderma species did not show any clear zone on Modified Pikovskaya's Agar (MPA) after incubation at room temperature for 0-7 days (Figure 1-a). Similarly, the study of Rawat and Tewari (2011) reported that Trichoderma species revealed good mycelial growth, but no halo-zone formation on the solid medium containing insoluble inorganic phosphorus source. In addition, Nautiyal (1999) reported that the criterion for isolation of phosphate solubilizers based on the formation of a visible halo-zone on Pikovskaya's agar is not a reliable technique because many isolates of Phosphate Solubilizing Microorganisms (PSM), which did not show any clear zone on agar plates, could be able to solubilize insoluble inorganic phosphates in liquid medium.

For the quantitative estimation of phosphate solubilization, all strains of Trichoderma species significantly provided P-solubilization in Modified Pikovskaya's Broth medium (MPB) as compared with a control (broth medium non-inoculated with Trichoderma strain) after incubation at room temperature for 7 days. Especially, Trichoderma strain FR-NST-009 gave the highest P-solubilization (80.25\%), followed by FR-NST-353 (77.51\%), CB-Pin-01 (66.91\%), RB-NST-028 (46.05\%), and RB-NST-003 (21.20\%), as compared with a control (Table 1). This study indicated that Trichoderma species have the ability to solubilize insoluble phosphate into soluble phosphate. Phosphate solubilization by Trichoderma species have been reported in a few researches (Akintokun et al., 2007; Kapri \& Tewari, 2010; Saravanakumar et al., 2013). 
Table 1. Final $\mathrm{pH}$, phosphorus concentration and P-solubilization percentage of Trichoderma species in the Modified Pikovskaya's Broth medium (MPB) supplemented with Rock Phosphate (RP) after incubation at room temperature for 7 days

\begin{tabular}{cccc}
\hline Treatments & $\begin{array}{c}\text { Final } \\
\mathrm{pH}\end{array}$ & $\begin{array}{c}\text { Phosphorus } \\
(\mathrm{mg}-\mathrm{P} / \mathrm{L})\end{array}$ & $\begin{array}{c}\text { P-solubilization } \\
(\%)\end{array}$ \\
\hline RB-NST-003 & $5.98 \mathrm{c}^{\mathrm{c}^{-}}$ & $6.25 \mathrm{c}^{\frac{1 /}{-}}$ & $21.20 \mathrm{~d}^{1 /}$ \\
RB-NST-028 & $6.42 \mathrm{~b}$ & $7.54 \mathrm{~b}$ & $46.05 \mathrm{c}$ \\
FR-NST-009 & $4.68 \mathrm{f}$ & $9.31 \mathrm{a}$ & $80.25 \mathrm{a}$ \\
FR-NST-353 & $5.12 \mathrm{~d}$ & $9.17 \mathrm{a}$ & $77.51 \mathrm{a}$ \\
CB-Pin-01 & $5.00 \mathrm{e}$ & $8.62 \mathrm{a}$ & $66.91 \mathrm{~b}$ \\
Control & $7.26 \mathrm{a}$ & $5.15 \mathrm{~d}$ & $0.00 \mathrm{e}$
\end{tabular}

${ }^{1 /}$ Values in the same column followed by the same alphabet are not significantly different from each other as analyzed by Duncan's Multiple Range Test at $\mathrm{P}<0.05$.

In addition, the treatments with Trichoderma species provided the final $\mathrm{pH}$ of broth culture lower than the control. The treatment with Trichoderma strain FR-NST-009 gave the lowest final pH (4.68), followed by CB-Pin-01 (5.00), FR-NST-353 (5.12), RB-NST-003 (5.98), and RB-NST-028 (6.42), while the final pH in control treatment was 7.26 (Table 1). The pH drop in PSM broth cultures has been reported in several researches which supports the pH change in the present study (Vazquez et al., 2000; Alam et al., 2002; Rashid et al., 2004; Pradham \& Sukla, 2005; Akintokun et al., 2007; Kapri \& Tewari, 2010; Yadav et al., 2011; Saravanakumar et al., 2013).

\subsection{Studying of Organic Acids Produced by Trichoderma Species}

For the qualitative estimation of organic acids produced by Trichoderma species, all strains of Trichoderma species could turn the Modified Pikovskaya's Agar (MPA) supplemented with bromocresol purple from purple to yellow in zones of acidification after incubation at room temperature for 7 days. Especially, Trichoderma species strains FR-NST-009, FR-NST-353, and CB-Pin-01 provided the yellow zones more than Trichoderma species strains RB-NST-003 and RB-NST-028 (Figure 1-b). This study supported by the experiment of Hoyos-Carvajal et al. (2009), Trichoderma species including T. harzianum, T. asperellum, T. virens, T. viridescens, T. longibrachiatum showed phosphate solubilization activity by acid production on agar media used tri-calcium phosphate as a phosphate source, with bromocresol purple $(100.0 \mathrm{mg} / \mathrm{L})$.

For the quantitative estimation of organic acids produced by Trichoderma species in broth medium, 3 kinds of organic acids including citric acid, lactic acid, and succinic acid were detected in all treatments inoculated with Trichoderma strain. However, the quantity of organic acids was significantly different when separated by the kind of organic acid and the strain of Trichoderma. Thus, Trichoderma species produced citric acid in higher than lactic acid and succinic acid. For citric acid, Trichoderma strain FR-NST-009 gave the highest value (612.23 mg/L), followed by CB-Pin-01 (514.01mg/L), FR-NST-353 (264.24 mg/L), RB-NST-003 (216.61 mg/L), and RB-NST-028 (191.53 mg/L). Trichoderma strain FR-NST-009 also gave the highest lactic acid (73.47 mg/L), followed by RB-NST-028 (52.69 mg/L), RB-NST-003 (51.46 mg/L), FR-NST-353 (49.80 mg/L), and CB-Pin-01 (42.20 mg/L). Finally, Trichoderma strain RB-NST-003 gave the highest succinic acid (16.37 mg/L), followed by CB-Pin-01 (16.31 mg/L), FR-NST-009 (14.54 mg/L), RB-NST-028 (13.67 mg/L), and FR-NST-353 (13.58 $\mathrm{mg} / \mathrm{L})$ (Table 2, Figure 2). 


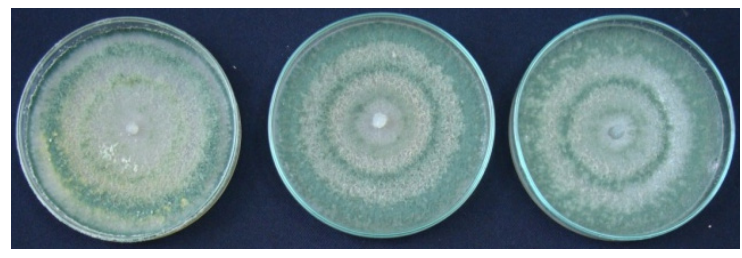

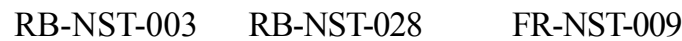

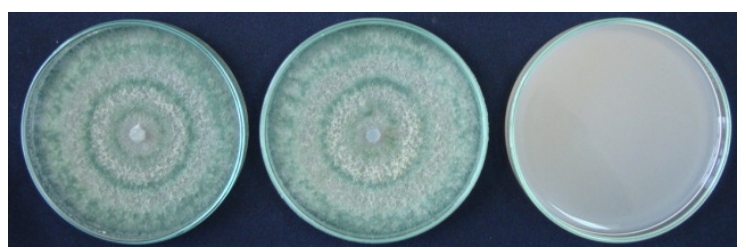

FR-NST-353
CB-Pin-01

(a)

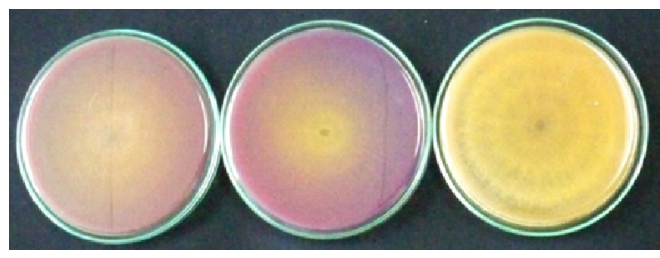

RB-NST-003 RB-NST-028 FR-NST-009

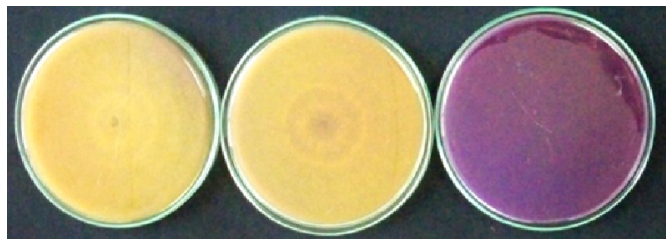

FR-NST-353
CB-Pin-01

(b)

Figure 1. Growth of Trichoderma species on Modified Pikovskaya's Agar (MPA) (a), phosphate solubilization activity by acid production of Trichoderma species on Modified Pikovskaya's Agar supplemented with bromocresol purple (b) after incubation at room temperature for 7 days

The previous results were supported with many reports that phosphate solubilizing microorganisms could produce several of organic acid for phosphate solubilization. For example, Aspergillus flavus, A. niger, and Penicillium cannescens produced oxalic, citric, gluconic, and succinic acid (Rashid et al., 2004); P. rugulosum, P. radicum, and $P$. variable produced gluconic acid (Reyes et al., 1999; Whitelaw et al., 1999; Vassilev et al., 1996); A. awamori, A. foetidus, A. terricola, A. amstelodemi, A. tamari, Bacillus polymyxa, and B. licheniformis produced oxalic and citric acid (Gupta et al., 1994). For organic acids produced by Trichoderma species, only the report of Akintokun et al. (2007) showed that T. isridae can produce acetic acid, citric acid, fumaric acid, gluconic acid, glutaric acid, lactic acid, maleic acid, malic acid, succinic acid, and tartaric acid. However, Alam et al. (2002) and Rashid et al. (2004) reported that oxalic and citric acids were two major acids produced by PSM.

In addition, the treatments with Trichoderma species significantly provided the final glucose concentration in broth culture lower than the control. The treatment with Trichoderma strain FR-NST-009 gave the lowest final glucose concentration $(3,722.30 \mathrm{mg} / \mathrm{L})$, followed by FR-NST-353 (3,894.43 mg/L), CB-Pin-01 (4,050.36 mg/L), RB-NST-003 (4,204.15 mg/L), and RB-NST-028 $(5,529.28 \mathrm{mg} / \mathrm{L})$; the glucose concentration in control treatment was $12,131.59 \mathrm{mg} / \mathrm{L}$ (Table 2, Figure 2). This result indicated that Trichoderma species used glucose as a carbon source for organic acid production; the glucose concentration decreasing correlated with organic acids increasing produced by Trichoderma strain. In this sense, Rashid et al. (2004) showed that PSM used glucose as a carbon source to solubilize insoluble phosphate by secreting organic acid. Furthermore, Nautiyal (1999) and Pradham and Sukla (2005) reported that glucose was the best carbon source of PSM for phosphate solubilization as compared with arabinose, fructose, galactose, sorbitol, mannitol, xylose, sucrose, maltose, lactose, and raffinose.

Table 2. Organic acids produced by Trichoderma species and glucose concentration in modified Pikovskaya's Broth (MPB) supplemented with Rock Phosphate (RP) after incubation at room temperature for 7 days

\begin{tabular}{ccccc}
\hline Treatments & $\begin{array}{c}\text { Citric acid } \\
(\mathrm{mg} / \mathrm{L})\end{array}$ & $\begin{array}{c}\text { Lactic acid } \\
(\mathrm{mg} / \mathrm{L})\end{array}$ & $\begin{array}{c}\text { Succinic acid } \\
(\mathrm{mg} / \mathrm{L})\end{array}$ & $\begin{array}{c}\text { Glucose } \\
(\mathrm{mg} / \mathrm{L})\end{array}$ \\
\hline RB-NST-003 & $216.61 \mathrm{~d}^{1 /}$ & $51.46 \mathrm{bc}^{1 /}$ & $16.37 \mathrm{a}^{\underline{1} /}$ & $4,204.15 \mathrm{c}^{\underline{1}}$ \\
RB-NST-028 & $191.53 \mathrm{e}$ & $52.69 \mathrm{~b}$ & $13.67 \mathrm{~b}$ & $5,529.28 \mathrm{~b}$ \\
FR-NST-009 & $612.23 \mathrm{a}$ & $73.47 \mathrm{a}$ & $14.54 \mathrm{~b}$ & $3,722.30 \mathrm{f}$ \\
FR-NST-353 & $264.24 \mathrm{c}$ & $49.80 \mathrm{c}$ & $13.58 \mathrm{~b}$ & $3,894.43 \mathrm{e}$ \\
CB-Pin-01 & $514.01 \mathrm{~b}$ & $42.20 \mathrm{~d}$ & $16.31 \mathrm{a}$ & $4,050.36 \mathrm{~d}$ \\
Control & $0.00 \mathrm{f}$ & $0.00 \mathrm{e}$ & $0.00 \mathrm{c}$ & $12,131.59 \mathrm{a}$ \\
\hline
\end{tabular}

1/Values in the same column followed by the same alphabet are not significantly different from each other as analyzed by Duncan's Multiple Range Test at $\mathrm{P}<0.05$. 

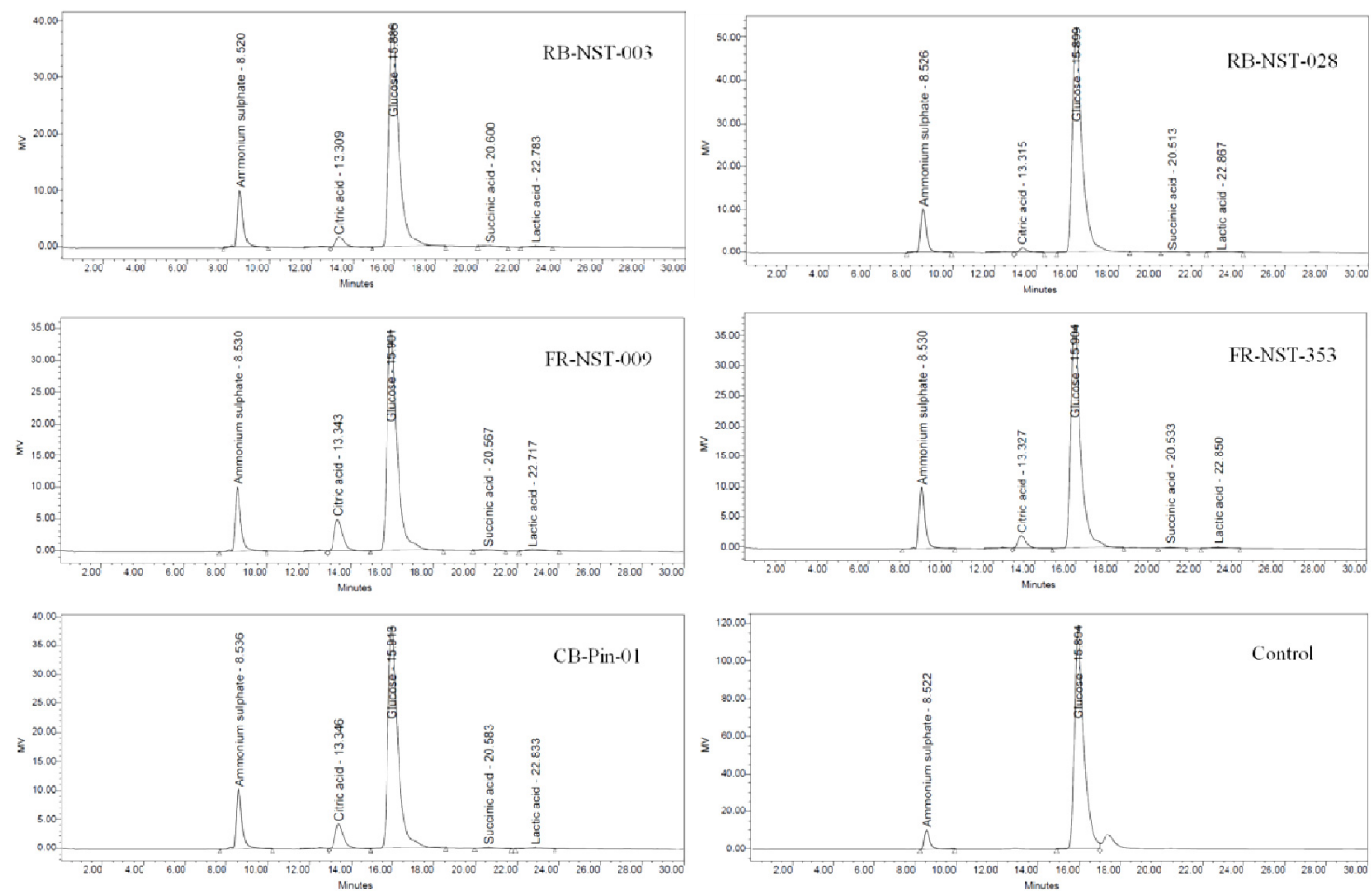

Figure 2. Chromatogram of organic acids produced by Trichoderma species and glucose utilization in the Modified Pikovskaya's Broth (MPB) supplemented with Rock Phosphate (RP) after incubation at room temperature for 7 days as compared with a control

Although the mechanisms of phosphate solubilization by microorganisms are still not fully understood, several mechanisms have been implicated in the operation. The organic acid production is an important mechanism in phosphate solubilization, but not the sole mechanism (Nautiyal et al., 1999; Alam et al., 2002). Production of organic acids results in acidification of microbial cell and its surroundings, and consequently, inorganic phosphate (PI) may be released from the insoluble phosphate forms, $\mathrm{Ca}_{3}\left(\mathrm{PO}_{4}\right)_{2}$ by the proton substitution for $\mathrm{Ca}^{2+}$ (Rodríguez \& Fraga, 1999). Other mechanisms include lowering of $\mathrm{pH}$ as a result of acid production, and ion chelation and exchange reaction (Akintokun et al., 2007). Additionally, phosphate solubilization of Trichoderma species may be occurred from phosphatase and phytase enzyme activity (Kapri \& Tewari, 2010; Saravanakumar et al., 2013).

\subsection{Testing of Phosphate Solubilization in vivo (Under Greenhouse Conditions)}

The efficacy of Trichoderma species and Rock Phosphate (RP) on the growth of rubber tree was conducted under greenhouse conditions between July, 2013-December, 2013. The plant height, stem circumference, and leaf number of 6-month-old rubber tree clone RRIM 600 used in the experiment in all treatments were not significantly different on the initial day of testing. The means of plant height, stem circumference, and leaf number were $60.56 \mathrm{~cm}, 3.84 \mathrm{~cm}$, and 32 leaves per plant (data not shown), respectively.

At 180 days after planting, the treatments with Trichoderma species and Rock Phosphate (RP) showed significant differences in growth and development parameter, population and root colonization of Trichoderma species, and chemical analysis as compared with control 1 (with only RP) and control 2 (without RP). The treatments with FR-NST-009+RP increased plant height (22.19\%), stem circumference (13.81\%), leaf number (71.43\%), as compared with the control 1. Moreover, the treatments with FR-NST-009+RP provided the total phosphorus in the rubber tree leaves more than the control 1 , with $18.90 \%$, while the treatments with CB-Pin-01+RP provided the total phosphorus in the rubber tree leaves more than the control 1, with $2.68 \%$ (Table 3 ). In addition, the treatments with FR-NST-009+RP increased shoot fresh weight (43.95\%), root fresh weight (19.36\%), shoot dry weight $(39.96 \%)$, and root dry weight $(21.13 \%)$, as compared with the control 1 (Table 4$)$. 
Table 3. Plant height, stem circumference, leaf number and total phosphorus in the leaves of the rubber tree after planting for 180 days in the testing of phosphate solubilization under greenhouse conditions

\begin{tabular}{|c|c|c|c|c|c|c|c|c|}
\hline \multirow{2}{*}{ Treatments } & \multicolumn{2}{|c|}{ Plant height } & \multicolumn{2}{|c|}{ Stem circumference } & \multicolumn{2}{|c|}{ Leaf number } & \multicolumn{2}{|c|}{ Total P in Leaves } \\
\hline & $(\mathrm{cm})$ & $(\%)$ & $(\mathrm{cm})$ & $(\%)$ & leaf/plant & $(\%)$ & ) $\mathrm{mg} / \mathrm{kg}($ & )$\%($ \\
\hline FR-NST-009+RP & $113.50 \mathrm{a}^{1 / /}$ & 24.38 & $6.58 \mathrm{a}^{\mathrm{1}^{\prime /}}$ & 21.18 & $129 \mathrm{a}^{\frac{1 /}{1}}$ & 84.29 & $2,886.25 \mathrm{a}^{1 /}$ & 30.47 \\
\hline CB-Pin-01+RP & $102.50 \mathrm{~b}$ & 12.33 & $6.40 \mathrm{a}$ & 17.86 & $103 \mathrm{ab}$ & 47.14 & $2,527.62 \mathrm{~b}$ & 14.25 \\
\hline Control $(1+\mathrm{RP}($ & $93.25 \mathrm{c}$ & 2.19 & $5.83 \mathrm{~b}$ & 7.37 & $79 \mathrm{bc}$ & 12.86 & $2,468.26 \mathrm{bc}$ & 11.57 \\
\hline Control 2-(RP) & $91.25 \mathrm{c}$ & 0.00 & $5.43 \mathrm{~b}$ & 0.00 & $70 \mathrm{c}$ & 0.00 & $2,212.27 \mathrm{c}$ & 0.00 \\
\hline
\end{tabular}

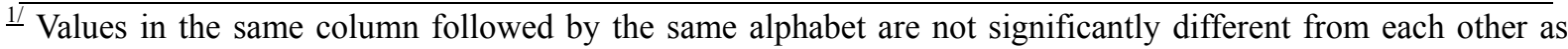
analyzed by Duncan's Multiple Range Test at $\mathrm{P}<0.05$.

Table 4. Shoot and root fresh weights, shoot and root dry weights of rubber tree after planting for 180 days in the testing of phosphate solubilization under greenhouse conditions

\begin{tabular}{|c|c|c|c|c|c|c|c|c|}
\hline \multirow{2}{*}{ Treatments } & \multicolumn{2}{|c|}{ Shoot fresh weight } & \multicolumn{2}{|c|}{ Shoot dry weight } & \multicolumn{2}{|c|}{ Root fresh weight } & \multicolumn{2}{|c|}{ Root dry weight } \\
\hline & (g/plant) & $(\%)$ & (g/plant) & $(\%)$ & (g/plant) & $(\%)$ & (g/plant) & $(\%)$ \\
\hline FR-NST-009+RP & $208.40 \mathrm{a}^{\mathrm{1}^{/ /}}$ & 54.52 & $59.54 \mathrm{a}^{\frac{1 /}{1}}$ & 54.29 & $140.52 \mathrm{a}^{1 /}$ & 22.61 & $45.99 \mathrm{a}^{\frac{1 /}{-}}$ & 23.36 \\
\hline CB-Pin-01+RP & $175.15 \mathrm{ab}$ & 29.87 & $53.48 \mathrm{ab}$ & 38.59 & $135.16 \mathrm{ab}$ & 17.93 & $44.05 \mathrm{a}$ & 18.16 \\
\hline Control (1+RP) & $149.13 \mathrm{~b}$ & 10.57 & $44.12 \mathrm{bc}$ & 14.33 & $118.34 \mathrm{~b}$ & 3.25 & $38.11 \mathrm{~b}$ & 2.23 \\
\hline Control 2-(RP( & $134.87 \mathrm{~b}$ & 0.00 & $38.59 \mathrm{c}$ & 0.00 & $114.61 \mathrm{~b}$ & 0.00 & $37.28 \mathrm{~b}$ & 0.00 \\
\hline
\end{tabular}

$1 /$ Values in the same column followed by the same alphabet are not significantly different from each other as analyzed by Duncan's Multiple Range Test at $\mathrm{P}<0.05$.

On the one hand, the treatments with Trichoderma strain FR-NST-009 provided the population of Trichoderma species in the planting medium with $2.73 \times 10^{7}, 2.15 \times 10^{6}, 5.00 \times 10^{5}$ and $1.78 \times 10^{5}$ Colony-Forming Units (CFU) per gram planting medium at $0,60,120$ and 180 days after planting, respectively. For the other hand, the treatments with T. harzianum strain CB-Pin-01 provided the population of Trichoderma species in the planting medium with $2.55 \times 10^{7}, 2.13 \times 10^{6}, 4.75 \times 10^{5}$ and $1.63 \times 10^{5} \mathrm{CFU} / \mathrm{g}$ planting medium at $0,60,120$ and 180 days after planting, respectively. However, the both treatments with Trichoderma strain FR-NST-009 and T. harzianum CB-Pin-01 provided the root colonization percentages with $100.00 \%$ (Table 5).

Table 5. Root colonization percentages at 180 days after planting, the population of Trichoderma species in the planting medium at 0-180 days after planting in the testing of phosphate solubilization under greenhouse conditions

\begin{tabular}{cccccc}
\hline \multirow{2}{*}{ Treatments } & Root colonization & \multicolumn{2}{c}{ Population of Trichoderma spp. (CFU/g planting medium) } \\
\cline { 3 - 5 } & )\%) & 0 day & 60 days & 120 days & 180 days \\
\hline FR-NST-009+RP & $100.00 \mathrm{a}^{\mathrm{a}^{-}}$ & $2.73 \times 10^{7} \mathrm{a}^{\underline{1}}$ & $2.15 \times 10^{6} \mathrm{a}$ & $5.00 \times 10^{5} \mathrm{a}$ & $1.78 \times 10^{5} \mathrm{a}$ \\
CB-Pin-01+RP & $100.00 \mathrm{a}$ & $2.55 \times 10^{7} \mathrm{a}$ & $2.13 \times 10^{6} \mathrm{a}$ & $4.75 \times 10^{5} \mathrm{a}$ & $1.63 \times 10^{5} \mathrm{a}$ \\
Control (1+RP( & $0.00 \mathrm{~b}$ & $0.0 \mathrm{~b}$ & $0.0 \mathrm{~b}$ & $0.0 \mathrm{~b}$ & $0.0 \mathrm{~b}$ \\
Control 2-(RP & $0.00 \mathrm{~b}$ & $0.0 \mathrm{~b}$ & $0.0 \mathrm{~b}$ & $0.0 \mathrm{~b}$ & $0.0 \mathrm{~b}$ \\
\hline
\end{tabular}

$1 /$ Values in the same column followed by the same alphabet are not significantly different from each other as analyzed by Duncan's Multiple Range Test at $\mathrm{P}<0.05$.

At 60 days after planting, the treatments with Trichoderma strain FR-NST-009 provided the percentage of available phosphorus increasing more than the control 1 at $14.91 \%$, while the treatments with T. harzianum strain CB-Pin-01 provided the percentage of available phosphorus increasing more than the control 1 at $11.08 \%$. However, after 60 days, the available phosphorus in the planting medium continually decreased in all treatments 
(Figure 3-a). The $\mathrm{pH}$ of the planting medium in all treatments continually decreased from the initial day of testing to $180 \mathrm{~d}$ after planting. The treatments with Trichoderma species and Rock Phosphate (RP) and control 1 gave the $\mathrm{pH}$ in planting medium higher than control 2 (Figure 3b).

These results indicated that Trichoderma species had ability to promote growth of rubber tree through phosphate solublilization. Growth promotion of Trichoderma species has been reported by many researchers. Thus, Yedidia et al. (2001) reported that $T$. harzianum strain T-203 increased root area $(95.00 \%)$, cumulative root length $(75.00 \%)$, dry weight $(80.00 \%)$, shoot length $(45.00 \%)$, and leaf area $(80.00 \%)$ of cucumber after sowing for 28 days in soil amended with T. harzianum. Additionally, Yadav et al. (2011) showed that T. harzianum significantly enhanced the shoot length $(61.56 \%)$, root length $(69.95 \%)$, shoot dry weight $(38.71 \%)$, and root dry weight $(57.58 \%)$ of chickpea as compared with the control. Moreover, Saravanakumar et al. (2013) reported that Trichoderma strain TSK8 enhanced total mangrove seedling biomass significantly by $48.00 \%, 19.00 \%$, and $11.00 \%$ when supplemented with soluble super phosphate $\left(\mathrm{KH}_{2} \mathrm{PO}_{4}\right)$, without any phosphate and insoluble tricalcium phosphate $\left(\mathrm{Ca}_{3}\left(\mathrm{PO}_{4}\right)_{2}\right)$, respectively.

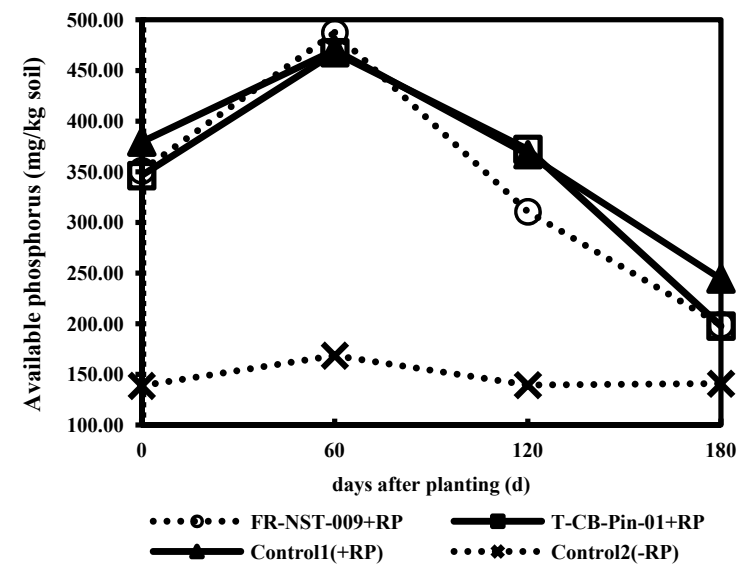

(a)

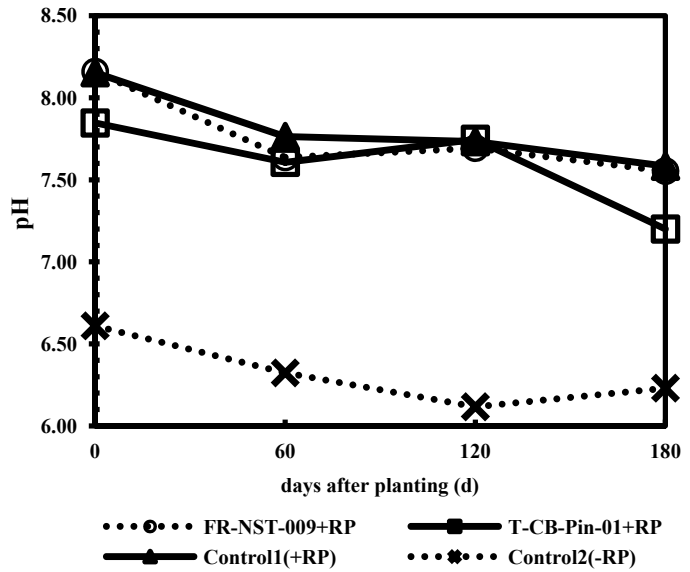

(b)

Figure 3. Available phosphorus (a), the $\mathrm{pH}$ of the planting medium (b) in the testing of phosphate solubilization under greenhouse conditions

Phosphate solublilization is one of the mechanisms of Tricoderma species for plant growth promotion, although other mechanisms of Tricoderma species to increase growth and yield of plants have been reported. For example, Windham et al. (1986) reported that Tricoderma species produced growth regulating factors, which enhanced seed germination and plant growth. Baker (1988) reported that such increases in plant growth and development may result from control of minor pathogens or increased nutrient uptake through enhanced root growth and promoted the availability of necessary nutrients. Also, Harman (2000) reported that T. harzianum strain T-22 was as effective as a commercial rooting hormone in inducing roots of plant, such as tomato and potato. Intana (2003) reported that inoculation of cucumber seedling with certain mutant strains derived through UV irradiation and wild type isolates of $T$. harzianum or treatment of cucumber seeds only with their purified metabolites (pentyl pyrone, harzianic acid or harzianic acid isomer) resulted in significant increases in the shoot and root fresh weights of cucumber seedlings. Yadav et al. (2011) reported that T. harzianum could produce Indole Acetic Acid (IAA) which effected on the growth of chickpea.

Furthermore, Trichoderma species had an ability to uptake phosphorus in plant. Yedidia et al. (2001) noted that $T$. harzianum strain T-203 increased the concentration of phosphorus in the shoots of cucumber with $90.00 \%$ after sowing for 28 days in soil amended with T. harzianum. Rudresh et al. (2005a, 2005b) reported that Trichoderma spp. ( $T$.harzianum, $T$. viride, and $T$. virens) could increase the quantity of phosphorus in chickpea when compared with the control both in greenhouse and field conditions.

Finally, Trichoderma strain FR-NST-009 was identified by morphological characteristics according to interactive key to species of Samuels et al. (2014). The results showed that Trichoderma strain FR-NST-009 was Trichoderma harzianum, which grew rapidly on PDA $(0.90 \mathrm{~mm} / \mathrm{h})$, showing white mycelia and green conidia. 
Conidia were sub-globose to ovoid, 2.7-3.5 $\mu \mathrm{m}$ in length and 2.5-3.0 $\mu \mathrm{m}$ in width, dry and smooth. Conidiophores were long central axis and lateral branches typically paired. Phialides were flask shape, 5.1-6.8 $\mu \mathrm{m}$ in length, enlarged in the middle, sharply constricted below the tip to form a narrow neck and slightly constricted at the base, and held in cruciate whorls of 2-4 (Figure 4). This study indicated that T. harzinum was the plant growth promoting and phosphate solubilizing fungi. Accordingly, T. harzinum has been used in bio-products in many countries such as USA, Japan, Canada, Germany, England, Denmark, Israel, and Thailand (Harman, 2000; Intana, 2003; Chamswarng, 2006).

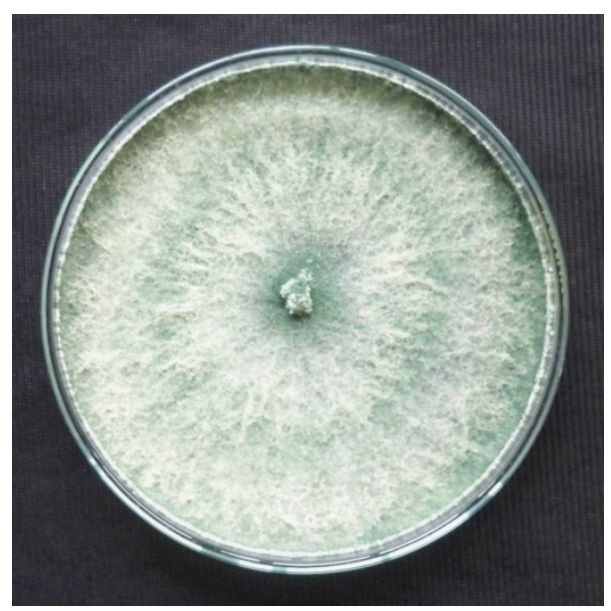

(a)

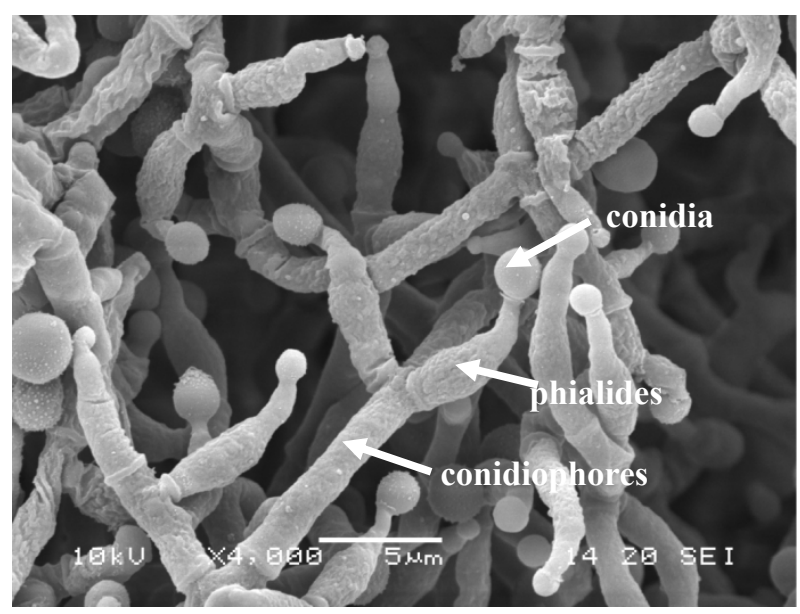

(b)

Figure 4. Characteristics of Trichoderma harzianum strain FR-NST-009; colony grew on potato dextrose agar after incubation at room temperature for 5 days (a), conidiophores, phialides and conidia observed under Scanning Electron Microscope-SEM (b)

\section{Conclusions}

Trichoderma species could solubilize insoluble phosphate into available phosphate through organic acid production and they could promote growth of rubber tree under greenhouse conditions, especially indigenous $T$. harzianum strain FR-NST-009.

\section{Acknowledgments}

This work was supported by the Office of the Higher Education Commission, Thailand Fund (Grant No. 10/2553) and Walailak University Fund (Grant No. 26/2556).

\section{References}

Afzal, A., \& Bano, A. (2008). Rhizobium and phosphate solubilizing bacteria improve the yield and phosphorus uptake in wheat (Triticum aestivum). International Journal of Agriculture and Biology, 10(1), 85-88.

Akintokun, A. K., Akande, G. A., Akintokun, P. O., Popoola, T. O. S., \& Babalola, A. O. (2007). Solubilization on insoluble phosphate by organic acid-producing fungi isolated from Nigerian soil. International Journal of Soil Science, 2(4), 301-307. http://dx.doi.org/ 10.3923/ijss.2007.301.307

Alam, S., Khalil, S., Ayub, N., \& Rashid, M. (2002). In vitro solubilization of inorganic phosphate by phosphate solubilizing microorganisms (PSM) from Maize rhizosphere. International Journal of Agriculture and Biology, 4(4), 454-458.

Altomare, C., Norvell, W. W., Bjorkman, T., \& Harman, G. E. (1999). Solubilization of phosphates and micronutrients by the plant-growth-promoting and biocontrol fungus Trichoderma harzianum Rifai 1295-22. Applied and Environmental Microbiology, 65(7), 2926-2933.

AOAC. (2000). Official Methods of Analysis of AOAC International : Secs. 993.13 (17th ed.). Gaithersburg, MD: AOAC international.

Baker, R. (1988). Trichoderma spp. as plant growth stimulants. CRC Critical Review of Biotechnology, 7(2), 97-106. 
Chakhatrakan, S., Promwee, A., Intana, W., \& Chamswarng, C. (2006). The effects of Trichoderma harzianum strain CB-Pin-01 fresh culture for growth promotion of vegetable amaranth. The 13th Tri-University International Joint Seminar and Symposium 2006 (pp. 146-149). Tsu, Japan: Mie University.

Chamswang, C. (2006). Biological Control of Plant Diseases. Nahkon Pathom, Thailand: Kasetsart University, Kamphaeng Saen Campus.

Chamswarng, C. Roungwiset, K., Paradornuwat, A., Hongprayoon, C., Choomjit, W., \& Chantarapannik, S. (1997). Potential of Trichoderma harzianum for reducing population of Phytophthora palmivora and improving health of root rot infected durian tree. The proceeding of 35th Kasetsart University annual conference (pp. 265-276). Bangkok, Thailand: Kasetsart University.

Chamswarng, C., \& Intanoo, W. (2002). Production of Trichoderma fresh culture by simple technique for controlling damping-off of yard long bean by Sclerotium rolfsii. The proceeding of 40th Kasetsart University annual conference (pp. 114-122). Bangkok, Thailand: Kasetsart University.

Chamswarng, C., \& Inwang, B. (1987). Control of Rhizoctonia damping-off cotton by seed coating with some microorganism. In The proceeding of 25th Kasetsart University annual conference (pp. 353-362). Bangkok, Thailand: Kasetsart University.

Chamswarng, C., Chana, C., Chuaiprasit, C., Cheevavitiyakul, S., \& Gesnara, W. (1990). Evaluation on the efficacy of Trichoderma harzianum for the biocontrol of Sclerotium blight of barley in natural field. The proceeding of 28th Kasetsart University annual conference (pp. 163-171). Bangkok, Thailand: Kasetsart University.

Dubey, S. C., Suresh, M., \& Singh, B. (2007). Evaluation of Trichoderma species against Fusarium oxysporum f. sp. ciceris for integrated management of chickpea wilt. Biological Control, 40(1), 118-127. http://dx.doi.org/10.1016/j.biocontrol.2006.06.006

Fiske, C. H., \& Subbarow, Y. (1925). The colorimetric determination of phosphorus. The Journal of Biological Chemistry, 66(2), 375-400.

Gupta, R. R., Singal, R., Shanker, A., Kuhad, R. C., \& Saxena, R. K. (1994). A modified plate assay for secreening phosphate solubilizing microorganisms. Journal of General and Applied Microbiology, 40(3), 255-260. http://dx.doi.org/10.2323/jgam.40.255

Harman, G. E. (2000). Myths and dogmas of biocontrol: Changes in perceptions derived from reseach on Trichoderma harzianum T-22. Plant Disease, 84(4), 377-393. http://dx.doi.org/ 10.1094/PDIS.2000.84.4.377

Hoyos-Carvajal, L., Orduz, S., \& Bissett, J. (2009). Growth stimulation in bean (Phaseolus vulgaris L.) by Trichoderma. Biological Control, 51(3), 409-416. http://dx.doi.org/10.1016/j.biocontrol.2009.07.018

Inbar, J., Abramsky, M., Cohen, D., \& Chet, I. (1994). Plant growth enhancement and disease control by Trichoderma harzianum in vegetable seedlings grown under commercial conditions. European Journal of Plant Pathology, 100(5), 337-346. http://dx.doi.org/10.1007/BF01876444

Intana, W. (2003). Selection and development of Trichoderma spp. for high glucanase, antifungal metabolites producing and plant growth promoting isolates for biological control of cucumber damping-off caused by Pythium spp. (Unpublished doctoral dissertation). Kasetsart University, Bangkok, Thailand.

Inwang, B., \& Chamswarng, C. (1986). Control of tomato stem rot (Sclerotium roffsii) in microorganisms isolated from the cultivated soils. The proceeding of 24th Kasetsart University annual conference (pp. 173-185). Bangkok, Thailand: Kasetsart University.

Kapri, A., \& Tewari, L. (2010). Phosphate solubilization potential and phosphatase activity of rhizospheric Trichoderma spp. Brazilian Journal of Microbiology, 41(3), 787-795. http://dx.doi.org/10.1590/S1517-83822010005000001

Kitjaideaw, A., Chamswarng, C., Paradornuwat, A., \& Sethpakdee, R. (2000). Efficacy of Trichoderma mix and Bacillus subtilis for the protection of Phytophthora root rot on tangerine. The proceeding of 38th Kasetsart University annual conference (pp. 192-201). Bangkok, Thailand: Kasetsart University.

Lamool, P. (2006). Efficacy of Trichoderma harzianum for the control of root rot of hydroponically grown lettuce caused by Pythium aphanidermatum (Unpublished master's thesis). Kasetsart University, Bangkok, Thailand.

Martin, J. P. (1950). Use of acid, rose bengal, and streptomycin in the plate method for estimating soil fungi. Soil Science, 69(3), 215-232. 
Morales-Payan, J. P., \& Stall, W. M. (2004). Papaya (Carica papaya) transplant growth is affected by a Trichoderma-based stimulator. Proceedings of the Florida State Horticultural Society, 117, 227-231.

Nallathambi, P., Umamaheswari, C., Thakore, B. B. L., \& More, T. A. (2009). Post-harvest management of ber (Ziziphus mauritiana Lamk) fruit rot (Alternaria alternata Fr. Keissler) using Trichoderma species, fungicides and their combinations. Crop Protection, 28(6), 525-532. http://dx.doi.org/10.1016/j.cropro.2009.02.002

Nautiyal, C. S. (1999). An efficient microbiological growth medium for screening phosphate solubilizing $\begin{array}{llll}\text { microorganisms. } & \text { FEMS } & \text { Licrobiology } & \text { 265-270. }\end{array}$ http://dx.doi.org/10.1111/j.1574-6968.1999.tb13383.x

Office of Agricultural Economics. (2014). Statistic of chemical fertilizer imported of Thailand in 2012. Retrieved April 19, 2014, from http://www.oae.go.th/ download/FactorOfProduct/Fertilizer_value49-54.html

Ousley, M. A., Lynch, J. M., \& Whipps, J. M. (1994). The effects of addition of Trichoderma inocula on flowering and shoot growth of bedding plants. Scientia Horticulturae, 59(2), 147-159. http://dx.doi.org/10.1016/0304-4238(94)90081-7

Pikovskaya, R. I. (1948). Mobilization of phosphorus in soil connection with the vital activity of some microbial species. Microbiologiya, 17, 362-370.

Pradham, N., \& Sukla, L. B. (2005). Solubilization of inorganic phosphates by fungi isolated from agriculture soil. African Journal of Biotechnology, 5(10), 850-854.

Promwee, A. (2008). Selection and development of Trichoderma spp. isolated from bamboo soil for control of damping-off disease and growth promotion of Chinese kale (Brassica alboglabra Bailey) (Unpublished master's thesis). Thammasat University, Bangkok, Thailand.

Promwee, A. (2011). Role of Trichoderma spp. as phosphate solubilizing microorganism. Thai Journal of Soils and Fertilizers, 33(1), 17-30.

Rabeendran, N., Moot, D. J., Jones, E. E., \& Stewart, A. (2000). Inconsistent growth. promotion of cabbage and lettuce from Trichoderma isolates. New Zealand Plant Protection, 53, 143-146.

Rashid, M., Khalil, S., Ayub, N., Alam, S., \& Latif, F. (2004). Organic acids production and phosphate solubilization by phosphate solubilizing microorganisms (PSM) under in vitro conditions. Pakistan Journal of Biological Sciences, 7(2), 187-196.

Rawat, R., \& Tewari, L. (2011). Effect of abiotic stress on phosphate solubilization by biocontrol fungus Trichoderma sp. Current Microbiology, 62(5), 1521-1526. http://dx.doi.org/10.1007/s00284-011-9888-2

Reyes, I., Bernier, L., Simard, R. R., \& Antoun, H. (1999). Effect of nitrogen source on the solubilization of different inorganic phosphates by an isolate of Penicillium rugulosum and two UV-induced mutants. FEMS Microbiology Ecology, 28(3), 281-290. http://dx.doi.org/ 10.1111/j.1574-6941.1999.tb00583.x

Rodríguez, H., \& Fraga, R. (1999). Phosphate solubilizing bacteria and their role in plant growth promotion. Biotechnology Advances, 17, 319-339.

Rojo, F. G., Reynoso, M. M., Ferez, M., Chulze, S. N., \& Torres, A. M. (2007). Biological control by Trichoderma species of Fusarium solani causing peanut brown root rot under field conditions. Crop Protection, 26(4), 549-555. http://dx.doi.org/10.1016/j.cropro.2006.05.006

Rosa, D. R., \& Herrera, C. J. L. (2009). Evaluation of Trichoderma spp. as biocontrol agents against avocado white root rot. Biological Control, 51(1), 66-71. http://dx.doi.org/10.1016/j.biocontrol.2009.05.005

Rudresh, D. L., Shivaprakash, M. K., \& Prasad, R. D. (2005a). Effect of combined application of Rhizobium, phosphate solubilizing bacterium and Trichoderma spp. on growth, nutrient uptake and yield of chickpea (Cicer aritenium L.). Applied Soil Ecology, 28(2), 139-146. http://dx.doi.org/10.1016/j.apsoil.2004.07.005

Rudresh, D. L., Shivaprakash, M. K., \& Prasad, R. D. (2005b). Tricalcium phosphate solubilizing abilities of Trichoderma spp. in relation to $\mathrm{P}$ uptake \& growth yield parameters of chickpea (Cicer arietinum L.). Canadian Journal of Microbiology, 51(3), 217-226. http://dx.doi.org/ 10.1139/w04-127

Samuels, G. J., Chaverri, P., Farr, D. F., \& McCray, E. B. (2014). Trichoderma online, systematic mycology and microbiology laboratory, ARS, USDA. Retrieved April 7, 2014, from http://nt.ars-grin.gov/taxadescriptions/ keys/TrichodermaIndex.cfm.

Sangsridum, K. (2003). Integrated application of Trichoderma spp. and Gliocladium sp. for biological control of soil borne plant pathogenic fungi (Unpublished master's thesis). Kasetsart University, Bangkok, Thailand. 
Saravanakumar, K., Arasu, V. S., \& Kathiresan, K. (2013). Effect of Trichoderma on soil phosphate solubilization and growth improvement of Avicennia marina. Aquatic Botany, 104, 101-105. http://dx.doi.org/10.1016/j.aquabot.2012.09.001

Sattasakulchai, S. (2009). Screening of indigenous microorganisms for the control of sheath rot of rice caused by Sarocladium oryzae (Unpublished master's thesis). Walailak University, Nakhon Si Thammarat, Thailand.

Schachtman, D. P., Reid, R. J., \& Ayling, S. M. (1998). Phosphate uptake by plants: From soil to cell. Plant Physiology, 116(2), 447-453. http://dx.doi.org/10.1104/pp.116.2.447

Thienkhao, A. (2007). Efficacies of Trichoderma spp. for the inhibition of Curvularia eragrostidis and the control of flower rusty spot on Dendrobium orchid (Unpublished master's thesis). Kasetsart University, Bangkok, Thailand.

Vassilev, N., Fenice, M., \& Federici, F. (1996). Rock phosphate solubilization with gluconic acid produced by immobilized Penicillium variabile P16. Biotechnology Techniques, 10(8), 585-588. http://dx.doi.org/10.1007/BF00157366

Vazquez, P., Holiguin, G., Puente, M. E., Lopez Cortes, A., \& Bashan, Y. (2000). Phosphate solubilizing microorganisms associated with the rhizosphere of mangroves in semi \& coastal lagoon. Biology and Fertility of Soils, 30, 460-468.

Whitelaw, M. A., Harden, T. J., \& Helyar, K. R. (1999). Phosphate solubilisation in solution culture by the soil fungus Penicillium radicum. Soil Biology and Biochemistry, 31(5), 655-665. http://dx.doi.org/10.1016/S0038-0717(98)00130-8

Windham, M. T., Elad, Y., \& Baker, R.) 1986). A mechanism for increased plant growth induced by Trichoderma spp. Phytopathology, 76, 518-521. http://dx.doi.org/ 10.1094/Phyto-76-518

Yadav, J., Verma, J. P., \& Tiwari, K. N. (2011). Plant growth promoting activities of fungi and their effect on chickpea plant growth. Asian Journal of Biological Sciences, 4(3), 291-299. http://dx.doi.org/10.3923/ajbs.2011.291.299

Yedidia, I., Srivastva, A. K., Kapulnik, Y., \& Chet, I. (2001). Effect of Trichoderma harzianum on microelement concentrations and increased growth of cucumber plants. Plant and Soil, 235(2), 235-242. http://dx.doi.org/10.1023/A:1011990013955

Yenjit, P., Intanoo, W., Chamswarng, C., Siripanich, J., \& Intana, W. (2004). Use of promising bacterial strains for controlling anthracnose on leaf and fruit of mango caused by Colletotrichum gloeosporioides. Walailak Journal of Science and Technology, 1(2), 56-69.

\section{Copyrights}

Copyright for this article is retained by the author(s), with first publication rights granted to the journal.

This is an open-access article distributed under the terms and conditions of the Creative Commons Attribution license (http://creativecommons.org/licenses/by/3.0/). 